Research Paper

\title{
A comparison of weekly versus 3-weekly cisplatin during concurrent chemoradiotherapy for locoregionally advanced nasopharyngeal carcinoma using intensity modulated radiation therapy: a matched study
}

\author{
Dong-Fang Meng1, 2*, Rui Sun ${ }^{3 *}$, Li-Xia Peng1,You-Sheng Huang4, Qin Yang1, Dong-Hua Luo1, 2, Wei-Han \\ $\mathrm{Hu}^{3}$, Fang-Yun $\mathrm{Xie}^{3}$, Wei Luo ${ }^{3}$, Chong Zhao' ${ }^{2}$, Ling Guo ${ }^{2}$, Hai-Qiang Mai², Ming-Yuan Chen²,Ping Xie ${ }^{1,2}$, \\ Li-Sheng Zheng ${ }^{1}$, Jun-Ping Yang1, 2, Yan Mei ${ }^{1}$, Yuan-Yuan Qiang ${ }^{1}$, Liang $\mathrm{Xu}^{1}$, Chang-Zhi Li1, Bi-Jun \\ Huang ${ }^{1}$, Chao-Nan Qian ${ }^{1,2}{ }^{\varpi}$, Rui Sun ${ }^{2}$
}

1. State Key Laboratory of Oncology in South China; Collaborative Innovation Center for Cancer Medicine, Sun Yat-Sen University Cancer Center, Guangzhou 510060, China;

2. Department of Nasopharyngeal Carcinoma, Sun Yat-Sen University Cancer Center, Guangzhou 510060, China;

3. Department of Radiation Oncology, Sun Yat-Sen University Cancer Center, Guangzhou 510060, China;

4. Zhongshan School of Medicine, Sun Yat-Sen University, Guangzhou 510060, China.

* First two authors contribute to the study equally.

$\triangle$ Corresponding authors: Dr. Rui Sun, Department of Nasopharyngeal Carcinoma, State Key Laboratory of Oncology in South China; Collaborative Innovation Center for Cancer Medicine, Sun Yat-Sen University Cancer Center, Guangzhou 510060, China. Email: sunrui@sysucc.org.cn And Dr. Chao-Nan Qian, Department of Nasopharyngeal Carcinoma, State Key Laboratory of Oncology in South China; Collaborative Innovation Center for Cancer Medicine, Sun Yat-Sen University Cancer Center, Guangzhou 510060, China. Email: qianchn@sysucc.org.cn

(C) Ivyspring International Publisher. This is an open access article distributed under the terms of the Creative Commons Attribution (CC BY-NC) license (https://creativecommons.org/licenses/by-nc/4.0/). See http://ivyspring.com/terms for full terms and conditions.

Received: 2017.06.06; Accepted: 2017.10.09; Published: 2018.01.01

\begin{abstract}
Purpose: To compare the long-term survival outcomes and acute toxicity between locoregionally advanced nasopharyngeal carcinoma (NPC) patients who received either weekly or 3-weekly cisplatin during concurrent chemoradiotherapy (CCRT).

Methods: Between November 2008 and August 2011, 241 biopsy-proved NPC patients receiving concurrent cisplatin with intensity modulated radiotherapy (IMRT) were included. 90 patients treated with 4-7 weeks of $30-40 \mathrm{mg} / \mathrm{m}^{2}$ cisplatin weekly were matched with 90 patients who received two or three cycles of $80 \mathrm{mg} / \mathrm{m}^{2}$ cisplatin three-weekly by sex, age, T stage, $\mathrm{N}$ stage, Karnosky performance score (KPS). IMRT was presented to the nasopharyngeal gross target volume at 66-72 Gy/30-32 fractions and those involved neck area at 60-66 Gy/30-32 fractions.

Results: The median follow-up time was 69 months (range, 2-91 months), and the 5-year overall survival (OS), disease-free survival (DFS), locoregional relapse-free survival (LRFS), and distant metastasis-free survival (DMFS) rates were $85.6 \%$ vs. $90.0 \%(P=0.207), 85.6 \%$ vs. $92.6 \%(P=0.152)$, $94.4 \%$ vs. $96.7 \%(P=0.411)$, and $88.9 \%$ vs. $95.6 \%(P=0.107)$ for the group treated weekly and 3 -weekly cisplatin, respectively. No statistically significant survival differences were found between the two treatment groups in both univariate and multivariate analyses. The similar incidence of acute toxicities was observed between two groups.

Conclusions: Concurrent cisplatin-based chemotherapy administered weekly or three-weekly in combination with IMRT leads to similar acute toxicities and long-term survival outcomes in locoregionally advanced NPC patients.
\end{abstract}

Key words: cisplatin regimen, nasopharyngeal carcinoma, IMRT, concurrent chemoradiotherapy. 


\section{Introduction}

NPC (nasopharyngeal carcinoma) is much more common in Southern China and Southeast Asia [1-3]. Radical radiotherapy can serve as an effective treatment strategy for NPC patients and the survival benefit will increase plus with concomitant platinum-based chemotherapy [4, 5]. Treatment failure in NPC is always resulted from recurrence and distant metastasis of patients. Recent advances in the management of locoregional recurrence show that to reduce distant metastasis rate via taking systemic therapies are becoming more crucial [6, 7]. Besides, NPC is more sensitive to systemic therapies in the contrast of other solid cancers, [8]. Therefore, U.S. National Comprehensive Cancer Network (NCCN) guidelines recommend platinum-based concurrent chemoradiotherapy (CCRT) in the absence or presence of adjuvant chemotherapy as the first-line treatment for NPCs [9].

Cisplatin-based regimens delivered either once every three weeks $\left(80-100 \mathrm{mg} / \mathrm{m}^{2}\right)$ or once per week $\left(30-40 \mathrm{mg} / \mathrm{m}^{2}\right)$ are regarded as standard clinical strategies for CCRT. The NPC-0099 clinical trial demonstrated that high cisplatin dosage is optimal to radiotherapy alone for advanced NPC patients in terms of overall survival (OS) and progression-free survival (PFS) [10]. However, this regimen normally resulted in acute adverse reactions which would limit use dosage. Weekly lower dose cisplatin schedule, as another alternative, is based on the assumption that weekly regimen is less toxic and equally effective as 3-weekly high dose cisplatin. A phase III randomized trial revealed that weekly regimen (cisplatin 40 $\mathrm{mg} / \mathrm{m}^{2}$ ) concurrent with radiotherapy (CRT) was more easier to tolerate for patients and showed survival benefits compared with radiotherapy (RT) alone [11]. Although CRT can be seen as the standard clinical strategies for NPC, the comparison of optimal dosing schema for cisplatin has not been conducted.

Therefore, we focused on the comparation of acute toxicities and long-term survival outcomes of weekly versus three-weekly administration of cisplatin accompanied with IMRT in locoregionally advanced NPC patients. Our findings will help to give optimal clinical CCRT treatment strategies in NPC.

\section{Materials and Methods}

\section{Patient Selection}

Our study retrospectively reviewed from 241 histologically confirmed NPC patients who were treated with CCRT from November 2008 to August 2011 at Sun Yat-sen University Cancer Center. Inclusion criteria for the patients consisted of (1) histologically confirmed NPC by biopsy of the nasopharynx, (2) no distant metastasis, (3) no treatment prior to admission, (4) no other tumor types or serious illnesses, (5) Karnofsky Performance Status (KPS) score $\geq 80$, (6) received only cisplatin during concurrent chemotherapy, and (7) received radical IMRT during the course of CCRT. This retrospective study was approved by the Clinical Research Ethics Committee of the Sun Yat-sen University Cancer Center, and all the patients provided written informed consent before treatment. All the methods were conducted in accordance with the approved guidelines in this study.

\section{Clinical Staging}

Routine staging included medical history, clinical examination of head and neck, direct fiberoptic nasopharyngoscopy, magnetic resonance imaging (MRI) of skull base and entire neck, chest radiography, whole-body bone scan, abdominal sonography, or positron emission tomography-computed tomography (PET/CT). All patients were restaged according to the 7 th edition of the International Union against Cancer/American Joint Committee on Cancer (UICC/AJCC) system [12].

\section{Radiotherapy}

All 241 patients received definitive IMRT at Sun Yat-sen University Cancer Center. Prescribed doses were 66-72 Gy at 2.12-2.43 Gy/fraction to planning target volume (PTVnx) of primary gross tumor volume (GTVnx), 64-70 Gy to PTVnd of involved lymph nodes (GTVnd), 60-63 Gy to PTV1 of high-risk clinical target volume (CTV1), and 54-56 Gy to PTV2 of low-risk clinical target volume (CTV2). All targets were treated simultaneously using the simultaneous integrated boost technique.

The radiation treatment planning was designed in accordance with previous studies conducted at the Sun Yat-sen University Cancer Center [13] [14].

\section{Chemotherapy}

The institutional guidelines recommended CCRT for stage III-IVa-b patients. Chemotherapy was carried out on the same day with IMRT, and the cisplatin regimen consisted of intravenous infusion (IV) of $80 \mathrm{mg} / \mathrm{m}^{2}$ cisplatin every 3 weeks or $30-40$ $\mathrm{mg} / \mathrm{m}^{2} \mathrm{IV}$ cisplatin weekly.

\section{Follow-Up and Statistical Analysis}

Patient follow-up was defined among the first day of treatment to last examination or death. The mainly adverse events of chemotherapy, which were classified and graded according to the Common Terminology Criteria for Adverse Events v3.0 
(CTCAE v3.0, http://evs.nci.nih.gov/ftp1/CTCAE/ CTCAE_4.03_2010-06-14_QuickReference_8.5x11.pdf) , were assessed from the time patients received first dose of cisplatin to at least 7 days after the last dose of cisplatin was administered. Reexamined at least every three months during first two years, with follow-up examinations every six months thereafter until death. End-points (time to first defining event) were overall survival (OS), disease-free survival (DFS), loco-regional relapse-free survival (LRRFS) and distant metastasis-free survival (DMFS).

The program Statistical Package for Social Sciences version 22 (SPSS Inc., Chicago, IL, USA) was used for analysis. The chi-square test was used to compare clinical characteristics, whereas the t-test was used to analyze continuous variables. Survival curves were estimated using the product limit method of Kaplan-Meier with the log-rank test. Univariate analysis was conducted using the log-rank test, and the multivariate Cox proportional hazards model was used to estimate hazard ratios (HR) and 95\% confidence intervals (CI). All statistical tests were two-sided, $P<0.05$ was considered significant.

\section{Results}

\section{Patient Characteristics}

We analyzed a total of 241 locoregionally advanced NPC patients who were treated with weekly or 3-weekly cisplatin CCRT between November 2008 and August 2011 at Sun Yat-sen University Cancer Center. For the entire cohort, 180 adult patients (114 males, and 66 females) received CRT for locally advanced NPC. The male-to-female ratio was 1.7:1; median age was 45 years old (range, 20-66 years old). The groups were well matched for sex, age, $\mathrm{T}$ stage, $\mathrm{N}$ stage, and KPS. The basic characteristics of patients who reached the study criteria are summarized in Table 1.

\section{Treatment and Adverse Effects}

In the weekly group, at least five weeks of CCRT with cisplatin (CDDP) was delivered to $82 / 90$ patients (91.1\%) and four weeks of CDDP was delivered to only $8 / 90$ patients $(8.9 \%)$. In the 3 -weekly group, two cycles of CDDP was finished by 86/90 patients (95.6\%) and three cycles of CDDP was completed by $4 / 90$ patients $(4.4 \%)$. The median cumulative cisplatin dose was 171.0 and $168.2 \mathrm{mg} / \mathrm{m}^{2}$ CDDP for the weekly and 3-weekly group, respectively $(p=0.426)$. There was no significant interaction between RT dose schedule, cisplatin regimen, and the cumulative mean cisplatin dose.

Table 1. Basic characteristics of the patients with advanced NPC receiving concurrent chemoradiotherapy.

\begin{tabular}{|c|c|c|c|c|c|c|}
\hline \multirow[t]{2}{*}{ Characteristic } & \multicolumn{3}{|l|}{ Unmatched } & \multicolumn{3}{|l|}{ Matched } \\
\hline & $\begin{array}{l}\text { Weekly cisplatin } \\
\text { No.(\%) }\end{array}$ & $\begin{array}{l}\text { 3-weekly cisplatin } \\
\text { No.(\%) }\end{array}$ & $P$ value & $\begin{array}{l}\text { Weekly cisplatin } \\
\text { No.(\%) }\end{array}$ & $\begin{array}{l}\text { 3-weekly cisplatin } \\
\text { No. }(\%)\end{array}$ & $P$ value \\
\hline Sex & & & 0.494 & & & 1.000 \\
\hline Male & 78 (68.4) & $92(72.4)$ & & 57 (63.6) & 57 (63.6) & \\
\hline Female & $36(31.6)$ & 35 (27.6) & & $33(36.7)$ & $33(36.7)$ & \\
\hline Age(years) & & & 0.358 & & & 0.724 \\
\hline Median & 45 & 44 & & 46 & 41 & \\
\hline Range & $21-66$ & $20-66$ & & $21-66$ & $20-62$ & \\
\hline $\mathrm{T}$ classification & & & 0.722 & & & 1.000 \\
\hline T1-2 & $23(20.2)$ & $28(22.0)$ & & $19(21.1)$ & $19(21.1)$ & \\
\hline T3-4 & $91(79.8)$ & $99(78.0)$ & & $71(78.9)$ & $71(78.9)$ & \\
\hline $\mathrm{N}$ classification & & & 0.154 & & & 1.000 \\
\hline N0-1 & $40(35.1)$ & $56(44.1)$ & & $40(44.4)$ & $40(44.4)$ & \\
\hline N2-3 & $74(64.9)$ & $71(55.9)$ & & $50(55.6)$ & $50(55.6)$ & \\
\hline Overall stage & & & 0.522 & & & 0.138 \\
\hline III & $83(72.8)$ & $100(78.7)$ & & $63(70.0)$ & $74(82.2)$ & \\
\hline IVA & $24(21.1)$ & $22(17.3)$ & & $20(22.2)$ & $13(14.5)$ & \\
\hline IVB & $7(6.1)$ & $5(4)$ & & $7(7.8)$ & $3(3.3)$ & \\
\hline WHO histological classification Type 2 & & & 0.242 & & & 0.494 \\
\hline Differentiated & $4(3.5)$ & $10(7.9)$ & & $3(3.3)$ & $6(6.7)$ & \\
\hline Undifferentiated & $110(96.5)$ & $117(92.1)$ & & $87(96.7)$ & $84(93.3)$ & \\
\hline KPS & & & 0.734 & & & 1.000 \\
\hline$<90$ & $30(26.3)$ & $31(24.4)$ & & $22(24.4)$ & $22(24.4)$ & \\
\hline$\geq 90$ & 84 (73.7) & 96 (75.6) & & $68(75.6)$ & 68 (75.6) & \\
\hline EBV DNA (copies/ml) & & & 0.225 & & & 0.450 \\
\hline$<1000$ & $69(60.5)$ & $67(52.8)$ & & $50(55.6)$ & 55 (61.1) & \\
\hline$\geq 1000$ & 45 (39.5) & $60(47.2)$ & & $40(44.4)$ & $35(38.9)$ & \\
\hline
\end{tabular}

$\mathrm{T}$ and $\mathrm{N}$ categories are according to the 7th edition of the International Union Against Cancer/American Joint Commission on Cancer staging system. Abbreviations: KPS, Karnofsky performance score; NPC, nasopharyngeal carcinoma. 
Table 2. Adverse events

\begin{tabular}{|c|c|c|c|c|c|}
\hline \multirow[t]{3}{*}{ Adverse Events } & \multicolumn{2}{|c|}{$\begin{array}{l}\text { Weekly cisplatin } \\
\mathrm{N}=90\end{array}$} & \multicolumn{2}{|c|}{$\begin{array}{l}\text { 3-weekly cisplatin } \\
\mathrm{N}=90\end{array}$} & \multirow[t]{3}{*}{$P$ value } \\
\hline & All Grades & Grade $\geq 3$ & All Grades & Grade $\geq 3$ & \\
\hline & \multicolumn{4}{|c|}{ number of patients (percent) } & \\
\hline Anemia & $18(20.0)$ & $2(2.2)$ & $22(24.4)$ & 0 & 0.473 \\
\hline Leukopenia & $59(65.6)$ & $12(13.3)$ & $52(57.8)$ & $11(12.2)$ & 0.283 \\
\hline Thrombocytopenia & $11(12.2)$ & $6(6.7)$ & $8(8.9)$ & $3(3.3)$ & 0.467 \\
\hline Dysphagia & $54(60.0)$ & $4(4.4)$ & $50(55.6)$ & $5(5.6)$ & 0.546 \\
\hline Xerostomia & $57(63.3)$ & 0 & $65(72.2)$ & $1(1.1)$ & 0.202 \\
\hline Nausea & $79(87.8)$ & $5(5.6)$ & $77(85.6)$ & $2(1.6)$ & 0.661 \\
\hline Vomiting & $70(77.8)$ & $2(2.2)$ & $65(72.2)$ & $3(3.3)$ & 0.389 \\
\hline Mucositis & $90(100.0)$ & $27(30.0)$ & $87(96.7)$ & $25(27.8)$ & 0.244 \\
\hline Upper respiratory infection & $4(4.4)$ & $1(1.1)$ & $2(2.2)$ & 0 & 0.678 \\
\hline Alopecia & 17 (18.9) & $3(3.3)$ & $11(12.2)$ & $1(1.1)$ & 0.217 \\
\hline Rash & $16(17.8)$ & $2(2.2)$ & 10 (11.1) & $2(1.6)$ & 0.203 \\
\hline Nephrotoxicity & $4(4.4)$ & 0 & $2(2.2)$ & 0 & 0.678 \\
\hline
\end{tabular}

$P$-values were calculated with the chi-square test (or Fisher's exact test, if indicated)

Adverse events are summarized in Table 2. No treatment-related deaths were observed in either cohort. Mucositis was the most commonly experienced toxicity, with grade 3 mucositis occurring in $27 / 90(30.0 \%)$ and $25 / 90(27.8 \%)$ of weekly and 3 -weekly groups, respectively $(P=0.742)$. A grade 3 or higher adverse event was occurred in 64/90 (71.1\%) and 53/90 (58.9\%) of weekly cisplatin group and 3 -weekly cisplatin group $(P=0.086)$. In conclusion, systemic toxicities were no difference in both groups.

\section{Patterns of Treatment Failure}

The median follow-up time for the cohort was 69 months (range, 2-91 months). The patterns of treatment failure are summarized in Table 3. Up to the last day of follow-up, 5/90 (5.6\%) patients in weekly group and 3/90 (3.3\%) in 3-weekly group developed local regional failure $(P=0.718) .13 / 90(14.4 \%)$ patients in weekly group and $9 / 90(10.0 \%)$ in 3-weekly group died $(P=0.363)$. Moreover, $10 / 90$ $(11.1 \%)$ in weekly group and $4 / 90(4.4 \%)$ in 3-weekly group experienced distant metastasis $(P=0.042)$. The majority of deaths were the consequence of NPC.

Table 3. Failure patterns for the 180 patients with advanced NPC receiving concurrent chemoradiotherapy.

\begin{tabular}{llll}
\hline Failure patterns & $\begin{array}{l}\text { Weekly cisplatin } \\
\text { No.(\%) }\end{array}$ & $\begin{array}{l}\text { 3-weekly } \\
\text { cisplatin } \\
\text { No.(\%) }\end{array}$ & $P$ value \\
\hline Locoregional only & $3(3.3)$ & $3(3.3)$ & 1.000 \\
Distant only & $8(8.9)$ & $4(4.4)$ & 0.232 \\
Locoregional + distant & $2(2.2)$ & $0(0)$ & 0.477 \\
Total locoregional & $5(5.6)$ & $3(3.3)$ & 0.718 \\
Total distant & $10(11.1)$ & $4(4.4)$ & 0.095 \\
Total failure & $13(14.4)$ & $7(7.8)$ & 0.155 \\
Total deaths & $13(14.4)$ & $9(10.0)$ & 0.363 \\
\hline
\end{tabular}

\section{Univariate and Multivariate Analysis}

The results of univariate analysis are presented in Table 4. Univariate analysis indicated that
EBV-DNA was significantly related to 5-year OS, DFS, and LFFRS. $\mathrm{T}$ and $\mathrm{N}$ category was significantly associated with 5-year DMFS. However, no significant differences in 5-year OS, DFS, LRRFS and DMFS were observed between patients with weekly cisplatin and 3-weekly cisplatin (Figure 1).

Multivariate analysis was performed to adjust for potential prognostic factors, including sex, age, $\mathrm{T}$ category, N category, KPS, EBV-DNA, and cisplatin regimen. EBV DNA was an independent prognostic factor for 5-year OS (HR, 2.994; 95\% CI, 1.189-7.536; $P$ $=0.020)$, DFS (HR, 3.800; 95\% CI, 1.452-9.946; $P=$ 0.007), and LRRFS (HR, 15.653; 95\% CI, 1.765-138.780; $P=0.013$; Table 5). Both univariate and multivariate analyses demonstrated that two cisplatin regimens had no difference in the risk of death and disease progression.

\section{Discussion}

In this retrospective study, we observed that cisplatin-based (both weekly and 3-weekly) CCRT led to similar OS, DFS, LFFRS, DMFS and acute toxicities in locoregionally advanced NPC patients receiving IMRT. EBV DNA had prognostic value in analysis of III/IV NPC.

NPC, especially of the undifferentiated type, are highly responsive to chemotherapy and radiotherapy [15]. CCRT is recommended as a standard treatment strategy for locoregionally advanced NPC [9]. Many previous studies analyzed clinical pharmacology of cisplatin, including dose accumulation and dose delivery, affects the long-term survival outcomes of patients with NPC receiving concurrent chemoradiotherapy $[16,17]$. In general, $200 \mathrm{mg} / \mathrm{m}^{2}$ cisplatin was an appropriate cumulative dose in retrospective studies of NPC and head and neck cancer [18]. In the prospective NPC-9901and NPC-9902 trials, cumulative cisplatin $200 \mathrm{mg} / \mathrm{m}^{2}$ in two concurrent cycles is adequate to improve 
local-free survival and OS compared with one cycle [19]. However, Ou et al. reported a total cisplatin dose $>300 \mathrm{mg} / \mathrm{m}^{2}$ was an independent prognostic factor for OS, DFS and DMFS in local advanced NPC. Most notably, a proportion of patients in this study also received induction or adjuvant chemotherapy [20]. Nevertheless, several prospective clinical trials have proven patients with locoregionally advanced NPC do not benefit from induction or adjuvant chemotherapy [21-23]. The lowest effectively cumulative cisplatin dose (CCD) in Ou et al. study may have been inflated by delivering cisplatin-based induction or adjuvant chemotherapy [20].

A

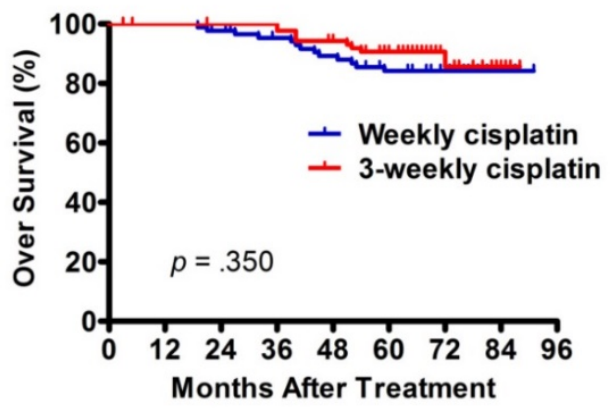

No. at risk

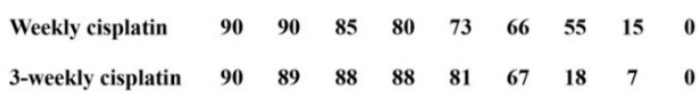

C



No. at risk

$\begin{array}{llllllllll}\text { Weekly cisplatin } & 90 & 90 & 85 & 80 & 73 & 66 & 55 & 15 & 0\end{array}$

$\begin{array}{llllllllll}\text { 3-weekly cisplatin } & 90 & 89 & 88 & 87 & 81 & 67 & 18 & 7 & 0\end{array}$
Several studies have analyzed the impact of the dose of cisplatin on clinical outcomes of NPC using conventional $2 \mathrm{D}$ and $3 \mathrm{D}$ conformal radiotherapy technology (CRT) [18, 24].Only few of reports addressed the impact of the dose of cisplatin on the clinical outcomes on patients with NPC who were treated with IMRT [25]. A retrospective study found that the number of cycles of cisplatin delivered is an independent prognostic factor in patients with stage II-III NPC undergoing CRT with weekly cisplatin; however, this previous study was mostly based on 2D or 3D CRT [18]. The impact of the cisplatin regimens on clinical outcomes of NPC remains controversy in this era of IMRT.

B

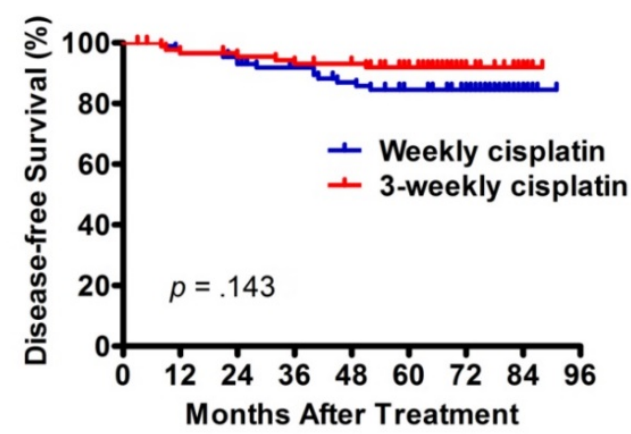

Figure 1. Kaplan-Meier OS (A), DFS (B), LRRFS (C), and DMFS (D) curves for patients with NPC stratified as the cisplatin regimen. Abbreviations: DFS, disease-free survival; DMFS, distant metastasis-free survival; LRRFS, local-regional relapse-free survival; OS, overall survival. 
Table 4. Univariate analysis of 5-year OS, DFS, LRRFS, and DMFS in the 180 patients with advanced NPC.

\begin{tabular}{|c|c|c|c|c|c|c|c|c|c|}
\hline Characteristic & No.(\%) & 5-year OS (\%) & $\mathrm{p}$ value & 5-year DFS (\%) & $\mathrm{p}$ value & 5-year LFFRS (\%) & $\mathrm{p}$ value & 5-year DMFS (\%) & $\mathrm{p}$ value \\
\hline Sex & & & 0.749 & & 0.782 & & 0.449 & & 0.522 \\
\hline Male & $114(63.3)$ & 86.8 & & 89.5 & & 96.4 & & 91.2 & \\
\hline Female & $66(36.7)$ & 89.4 & & 87.9 & & 90.9 & & 93.9 & \\
\hline Age (years) & & & 0.823 & & 0.678 & & 0.665 & & 0.066 \\
\hline$<45$ & $84(46.7)$ & 89.3 & & 86.9 & & 96.4 & & 88.1 & \\
\hline$\geq 45$ & $96(53.3)$ & 86.4 & & 90.6 & & 94.8 & & 95.8 & \\
\hline $\mathrm{T}$ category & & & 0.371 & & 0.095 & & 0.251 & & 0.045 \\
\hline T1-2 & $38(21.1)$ & 84.2 & & 81.6 & & 92.1 & & 84.2 & \\
\hline T3-4 & $142(78.9)$ & 88.7 & & 90.2 & & 96.5 & & 94.3 & \\
\hline N category & & & 0.137 & & 0.169 & & 0.794 & & 0.035 \\
\hline N0-1 & $80(44.4)$ & 91.3 & & 92.5 & & 95.0 & & 97.5 & \\
\hline N2-3 & $100(55.6)$ & 85.0 & & 86.0 & & 96.0 & & 88.0 & \\
\hline KPS & & & 0.349 & & 0.628 & & 0.403 & & 0.164 \\
\hline$<90$ & $44(24.4)$ & 84.1 & & 90.9 & & 93.2 & & 97.7 & \\
\hline$\geq 90$ & $136(75.6)$ & 88.9 & & 88.2 & & 96.3 & & 90.4 & \\
\hline Cisplatin regimen & & & 0.207 & & 0.152 & & 0.411 & & 0.107 \\
\hline Weekly cisplatin & $90(50.0)$ & 85.6 & & 85.6 & & 94.4 & & 88.9 & \\
\hline 3-weekly cisplatin & $90(50.0)$ & 90.0 & & 92.2 & & 96.7 & & 95.6 & \\
\hline EBV DNA (copies/ml) & & & 0.016 & & 0.010 & & 0.026 & & 0.198 \\
\hline$<1000$ & $105(58.3)$ & 93.3 & & 94.3 & & 99.0 & & 94.3 & \\
\hline$\geq 1000$ & $75(41.7)$ & 80 & & 81.3 & & 90.7 & & 89.3 & \\
\hline
\end{tabular}

$p$ values were calculated by using the log-rank test. T and $\mathrm{N}$ categories are according to the 6th edition of the International Union Against Cancer/ American Joint Commission on Cancer staging system.

Abbreviations: DFS, disease-free survival; DMFS, distant metastasis-free survival; IMRT, intensity-modulated radiotherapy; KPS, Karnofsky performance score; LRRFS, locoregional relapse-free survival; NPC, nasopharyngeal carcinoma; OS, overall survival; RT, radiotherapy.

The optimal cisplatin schedule for CCRT in NPC is the weekly or 3-weekly regimen. In our study, $2.34 \%(3 / 90)$ patients completed all 7 cycles of weekly cisplatin as planned and $4.4 \%(4 / 90)$ patients completed all 3 cycles of 3 -weekly cisplatin as planned. Reductions in the number of chemotherapy cycles were mostly due to patient refusal, severe mucositis, or prolonged severe leucopenia. Ho et al. described the dose intensity, delays and toxicity of CDDP administered weekly and 3-weekly concurrently with locally advanced squamous head and neck cancer (SCCHN) [26]. They found that delivery of $100 \mathrm{mg} / \mathrm{m}^{2}$ Cisplatin 3-weekly with radiotherapy was less tolerated than $40 \mathrm{mg} / \mathrm{m}^{2}$ CDDP weekly or $80 \mathrm{mg} / \mathrm{m}^{2}$ CDDP every three weeks and resulted in less patients achieving cumulative dose beyond $200 \mathrm{mg} / \mathrm{m}^{2}$, potentially lowering chemotherapy dose intensity. Therefore, the optimal CDDP dose in CCRT regimes for NPC needs to further exploration.

Cisplatin is the most common antineoplastic drug used for the concurrent chemoradiotherapy in NPC $[27,28]$. The most frequent adverse effects of cisplatin detected $(\sim 72 \%)$ involved the gastrointestinal apparatus and constitutional symptoms (fever, hyposthenia, asthenia, weight loss and sleep-wake rhythm alterations) [29]. Several other studies showed higher percentage of severe mucositis in patients treated with weekly cisplatin compared to patients treated with 3-weekly cisplatin [30]. Although our analysis showed no statistically significant differences in both groups, there was a slightly higher incidence of grade 3-4 hematological toxicity and oropharyngeal mucositis in the weekly CDDP group. The reason for these results may be the short time intervals, inadequate monitoring of blood counts and poor oral care in outpatients in the weekly CDDP group.

Nowadays, IMRT has almost replaced 2D-RT or 3D-CRT and is becoming the mainstream treatment for non-metastatic NPC [31, 32]. Moon et al. compared treatment outcomes of 2D-RT, 3D-CRT, and IMRT in patients with NPC [33]. They showed that 3D-CRT and IMRT were associated with a better local PFS and OS than 2D-RT in NPC, and IMRT found to have a superior OS for advanced primary tumors (T3-4). Meanwhile, cisplatin as a radiation sensitizer combined with IMRT is effective in tumor control, survival, prognostic indicators, and toxicity in the treatment of advanced head and neck cancers.

The major deficiency of this study is limited by its retrospective nature. The sample bias may exist because the clinical data was from a single institution. One important finding in this study was that weekly low-dose cisplatin treatment had about a $6.7 \%$ higher risk of distant metastasis than 3-weekly cisplatin group, even though the difference was not significant. The underlying molecular mechanism could be complicated, as the biological impact of low-dose cisplatin is much less studied in contrast to high-dose, cancer cell-killing effect. More endeavors are warranted for unveiling the biological impact of low-dose cisplatin treatment. 
Table 5. Multivariate analysis of variables correlated with clinical outcomes in the 180 patients with locoregionally advanced NPC.

\begin{tabular}{|c|c|c|c|}
\hline Endpoints & HR & $95 \% \mathrm{CI}$ & $P$ value \\
\hline \multicolumn{4}{|l|}{ OS } \\
\hline $\begin{array}{l}\text { Sex } \\
\text { Male vs. Female }\end{array}$ & 1.284 & $0.515-3.200$ & 0.591 \\
\hline $\begin{array}{l}\text { Age } \\
<45 \text { vs. } \geq 45\end{array}$ & 1.081 & $0.455-2.571$ & 0.860 \\
\hline $\begin{array}{l}\text { T category } \\
\text { T3-4 vs. T1-2 }\end{array}$ & 0.798 & $0.282-2.259$ & 0.671 \\
\hline $\begin{array}{l}\text { N category } \\
\text { N0-1 vs. N2-3 }\end{array}$ & 1.615 & $0.554-4.707$ & 0.380 \\
\hline $\begin{array}{l}\text { KPS } \\
<90 \text { vs. } \geq 90\end{array}$ & 0.738 & $0.293-1.859$ & 0.519 \\
\hline $\begin{array}{l}\text { Cisplatin regimen } \\
\text { Weekly cisplatin vs. } \\
\text { 3-weekly cisplatin }\end{array}$ & 0.547 & $0.225-1.333$ & 0.184 \\
\hline $\begin{array}{l}\text { EBV DNA (copies/ml) } \\
<1000 \text { vs. } \geq 1000\end{array}$ & 2.994 & $1.189-7.536$ & 0.020 \\
\hline DFS & & & \\
\hline $\begin{array}{l}\text { Sex } \\
\text { Male vs. Female }\end{array}$ & 0.950 & $0.382-2.360$ & 0.912 \\
\hline $\begin{array}{l}\text { Age } \\
<45 \text { vs. } \geq 45\end{array}$ & 0.649 & $0.267-1.574$ & 0.339 \\
\hline $\begin{array}{l}\text { T category } \\
\text { T3-4 vs. T1-2 }\end{array}$ & 0.527 & $0.183-1.515$ & 0.234 \\
\hline $\begin{array}{l}\text { N category } \\
\text { N0-1 vs. N2-3 }\end{array}$ & 1.345 & 0.441-4.102 & 0.603 \\
\hline $\begin{array}{l}\text { KPS } \\
<90 \text { vs. } \geq 90\end{array}$ & 1.548 & $0.508-4.720$ & 0.442 \\
\hline $\begin{array}{l}\text { Cisplatin regimen } \\
\text { Weekly cisplatin vs. } \\
\text { 3-weekly cisplatin }\end{array}$ & 0.507 & $0.199-1.291$ & 0.155 \\
\hline $\begin{array}{l}\text { EBV DNA (copies/ml) } \\
<1000 \text { vs. } \geq 1000\end{array}$ & 3.800 & $1.452-9.946$ & 0.007 \\
\hline LRRFS & & & \\
\hline $\begin{array}{l}\text { Sex } \\
\text { Male vs. Female }\end{array}$ & 0.607 & $0.149-2.463$ & 0.484 \\
\hline $\begin{array}{l}\text { Age } \\
<45 \text { vs. } \geq 45\end{array}$ & 1.443 & $0.339-6.133$ & 0.620 \\
\hline $\begin{array}{l}\text { T category } \\
\text { T3-4 vs. T1-2 }\end{array}$ & 0.150 & $0.015-1.471$ & 0.103 \\
\hline $\begin{array}{l}\text { N category } \\
\text { N0-1 vs. N2-3 }\end{array}$ & 0.145 & $0.013-1.565$ & 0.112 \\
\hline $\begin{array}{l}\text { KPS } \\
<90 \\
\geq 90\end{array}$ & 0.431 & 0.096-1.939 & 0.273 \\
\hline $\begin{array}{l}\text { Cisplatin regimen } \\
\text { Weekly cisplatin } \\
\text { 3-weekly cisplatin }\end{array}$ & 0.341 & $0.071-1.628$ & 0.177 \\
\hline $\begin{array}{l}\text { EBV DNA (copies/ml) } \\
<1000 \\
\geq 1000 \\
\text { DMFS }\end{array}$ & 15.653 & $1.765-138.780$ & 0.013 \\
\hline $\begin{array}{l}\text { Sex } \\
\text { Male vs. Female }\end{array}$ & 1.442 & $0.439-4.736$ & 0.547 \\
\hline $\begin{array}{l}\text { Age } \\
<45 \text { vs. } \geq 45\end{array}$ & 0.368 & 0.113-1.196 & 0.096 \\
\hline $\begin{array}{l}\text { T category } \\
\text { T3-4 vs. T1-2 }\end{array}$ & 0.589 & 0.189-1.837 & 0.362 \\
\hline $\begin{array}{l}\text { N category } \\
\text { N0-1 vs. N2-3 }\end{array}$ & 3.827 & $0.768-19.066$ & 0.101 \\
\hline $\begin{array}{l}\text { KPS } \\
<90 \text { vs. } \geq 90\end{array}$ & 4.919 & $0.631-38.371$ & 0.129 \\
\hline $\begin{array}{l}\text { Cisplatin regimen } \\
\text { Weekly cisplatin vs. } \\
\text { 3-weekly cisplatin }\end{array}$ & 0.399 & $0.124-1.285$ & 0.124 \\
\hline $\begin{array}{l}\text { EBV DNA }(\text { copies } / \mathrm{ml}) \\
<1000 \text { vs. } \geq 1000\end{array}$ & 2.312 & $0.796-6.714$ & 0.124 \\
\hline
\end{tabular}

In the present study, weekly regimen achieved equivalent acute toxicities and long-term survival outcomes compared with 3-weekly regimen in patients with locoregionally advanced NPC receiving single-agent cisplatin-based CCRT.

\section{Acknowledgements}

This work was supported by grants from the National Natural Science Foundation of China (No. 81672872 , No. 81272340 and No. 81472386 to C.Q., No. 81572901 to B.H., No. 81572848 to L.G., No. 81402248 to D.L., No. 81672665 to F.X.), the Science and Technology Planning Project of Guangdong Province, China (No. 2014B020212017, No. 2014B050504004 and No. 2015B050501005 to C.Q., and No. 2014A020209024 to B.H.), and the Provincial Natural Science Foundation of Guangdong, China (No. 2016A030311011 to C.Q.).

\section{Ethical approval}

This study was performed in accordance with the ethical standards as laid down in the 1964 Declaration of Helsinki and its later amendments or similar ethical standards.

\section{Informed consent}

Informed consent was obtained from all patients included in the study.

\section{Notes}

The authenticity of this article has been validated by uploading the key raw data onto the Research Data Deposit public platform (www.researchdata.org.cn), with the approval RDD number as RDDA2017000118.

\section{Competing Interests}

The authors have declared that no competing interest exists.

\section{References}

1. Huang PY, Zeng Q, Cao KJ, Guo X, Guo L, Mo HY, et al. Ten-year outcomes of a randomised trial for locoregionally advanced nasopharyngeal carcinoma: A single-institution experience from an endemic area. European journal of cancer. 2015; 51: 1760-70.

2. Zhang LF, Li YH, Xie SH, Ling W, Chen SH, Liu Q, et al. Incidence trend of nasopharyngeal carcinoma from 1987 to 2011 in Sihui County, Guangdong Province, South China: an age-period-cohort analysis. Chinese journal of cancer. 2015 ; 34: 350-7.

3. Sarmiento MP, Mejia MB. Preliminary assessment of nasopharyngeal carcinoma incidence in the Philippines: a second look at published data from four centers. Chinese journal of cancer. 2014; 33: 159-64.

4. Li WF, Chen L, Sun Y, Ma J. Induction chemotherapy for locoregionally advanced nasopharyngeal carcinoma. Chinese journal of cancer. 2016; 35: 94.

5. Meng DF, Xie P, Peng LX, Sun R, Luo DH, Chen QY, et al. CDC42-interacting protein 4 promotes metastasis of nasopharyngeal carcinoma by mediating invadopodia formation and activating EGFR signaling. Journal of experimental \& clinical cancer research : CR. 2017; 36: 21.

6. Lee AW, Ng WT, Chan LL, Hung WM, Chan CC, Sze HC, et al. Evolution of treatment for nasopharyngeal cancer--success and setback in the intensity-modulated radiotherapy era. Radiotherapy and oncology : journal of the European Society for Therapeutic Radiology and Oncology. 2014; 110: 377-84.

7. Huncharek M, Kupelnick B. In regards to Baujat et al.: Chemotherapy in locally advanced nasopharyngeal carcinoma: An individual patient data 
meta-analysis of eight randomized trials and 1753 patients (Int J Radiat Oncol Biol Phys 2006;64:47-56). International journal of radiation oncology, biology, physics. 2006; 65: 958; author reply -9 .

8. Lee N, Xia P, Quivey JM, Sultanem K, Poon I, Akazawa C, et al Intensity-modulated radiotherapy in the treatment of nasopharyngeal carcinoma: an update of the UCSF experience. International journal of radiation oncology, biology, physics. 2002; 53: 12-22.

9. Shah BA, Qureshi MM, Jalisi S, Grillone G, Salama A, Cooley T, et al. Analysis of decision making at a multidisciplinary head and neck tumor board incorporating evidence-based National Cancer Comprehensive Network (NCCN) guidelines. Practical radiation oncology. 2016; 6: 248-54.

10. Al-Sarraf M, LeBlanc M, Giri PG, Fu KK, Cooper J, Vuong T, et al. Chemoradiotherapy versus radiotherapy in patients with advanced nasopharyngeal cancer: phase III randomized Intergroup study 0099. Journal of clinical oncology : official journal of the American Society of Clinical Oncology. 1998; 16: 1310-7.

11. Chan AT, Teo PM, Ngan RK, Leung TW, Lau WH, Zee B, et al. Concurrent chemotherapy-radiotherapy compared with radiotherapy alone in locoregionally advanced nasopharyngeal carcinoma: progression-free survival analysis of a phase III randomized trial. Journal of clinical oncology : official journal of the American Society of Clinical Oncology. 2002; 20: 2038-44.

12. Edge SB, Compton CC. The American Joint Committee on Cancer: the 7th edition of the AJCC cancer staging manual and the future of TNM. Annals of surgical oncology. 2010; 17: 1471-4.

13. Sun X, Su S, Chen C, Han F, Zhao C, Xiao W, et al. Long-term outcomes of intensity-modulated radiotherapy for 868 patients with nasopharyngeal carcinoma: an analysis of survival and treatment toxicities. Radiotherapy and oncology : journal of the European Society for Therapeutic Radiology and Oncology. 2014; 110: 398-403.

14. Zhao C, Han F, Lu LX, Huang SM, Lin CG, Deng XW, et al. [Intensity modulated radiotherapy for local-regional advanced nasopharyngeal carcinoma]. Ai zheng $=$ Aizheng $=$ Chinese journal of cancer. 2004; 23: 1532-7.

15. Vokes EE, Liebowitz DN, Weichselbaum RR. Nasopharyngeal carcinoma. Lancet. 1997; 350: 1087-91.

16. Peng $\mathrm{H}$, Chen L, Li WF, Guo R, Mao YP, Zhang $\mathrm{Y}$, et al. The Cumulative Cisplatin Dose Affects the Long-Term Survival Outcomes of Patients with Nasopharyngeal Carcinoma Receiving Concurrent Chemoradiotherapy. Scientific reports. 2016; 6: 24332

17. Jagdis A, Laskin J, Hao D, Hay J, Wu J, Ho C. Dose delivery analysis of weekly versus 3-weekly cisplatin concurrent with radiation therapy for locally advanced nasopharyngeal carcinoma (NPC). American journal of clinical oncology. 2014; 37: 63-9.

18. Loong HH, Ma BB, Leung SF, Mo F, Hui EP, Kam MK, et al. Prognostic significance of the total dose of cisplatin administered during concurrent chemoradiotherapy in patients with locoregionally advanced nasopharyngeal carcinoma. Radiotherapy and oncology : journal of the European Society for Therapeutic Radiology and Oncology. 2012; 104: 300-4.

19. Lee AW, Tung SY, Ngan RK, Chappell R, Chua DT, Lu TX, et al. Factors contributing to the efficacy of concurrent-adjuvant chemotherapy for locoregionally advanced nasopharyngeal carcinoma: combined analyses of NPC-9901 and NPC-9902 Trials. European journal of cancer. 2011; 47: 656-66.

20. Ou X, Zhou X, Shi Q, Xing X, Yang Y, Xu T, et al. Treatment outcomes and late toxicities of 869 patients with nasopharyngeal carcinoma treated with definitive intensity modulated radiation therapy: new insight into the value of total dose of cisplatin and radiation boost. Oncotarget. 2015; 6: 38381-97.

21. Fountzilas G, Ciuleanu E, Bobos M, Kalogera-Fountzila A, Eleftheraki AG, Karayannopoulou $\mathrm{G}$, et al. Induction chemotherapy followed by concomitant radiotherapy and weekly cisplatin versus the same concomitant chemoradiotherapy in patients with nasopharyngeal carcinoma: a randomized phase II study conducted by the Hellenic Cooperative Oncology Group (HeCOG) with biomarker evaluation. Annals of oncology : official journal of the European Society for Medical Oncology. 2012; 23: 427-35.

22. Hareyama M, Sakata K, Shirato H, Nishioka T, Nishio M, Suzuki K, et al. A prospective, randomized trial comparing neoadjuvant chemotherapy with radiotherapy alone in patients with advanced nasopharyngeal carcinoma. Cancer. 2002; 94: 2217-23.

23. International Nasopharynx Cancer Study G, Trial VI. Preliminary results of a randomized trial comparing neoadjuvant chemotherapy (cisplatin, epirubicin, bleomycin) plus radiotherapy vs. radiotherapy alone in stage $\operatorname{IV}(>$ or $=\mathrm{N} 2$, M0) undifferentiated nasopharyngeal carcinoma: a positive effect on progression-free survival. International journal of radiation oncology, biology, physics. 1996; 35: 463-9.

24. Jen YM, Shih R, Lin YS, Su WF, Ku CH, Chang CS, et al. Parotid gland-sparing 3-dimensional conformal radiotherapy results in less severe dry mouth in nasopharyngeal cancer patients: a dosimetric and clinical comparison with conventional radiotherapy. Radiotherapy and oncology : journal of the European Society for Therapeutic Radiology and Oncology. 2005; 75: 204-9.

25. Peng H, Chen L, Zhang Y, Li WF, Mao YP, Zhang F, et al. Prognostic Value of the Cumulative Cisplatin Dose During Concurrent Chemoradiotherapy in Locoregionally Advanced Nasopharyngeal Carcinoma: A Secondary Analysis of a Prospective Phase III Clinical Trial. The oncologist. 2016.

26. Ho KF, Swindell R, Brammer CV. Dose intensity comparison between weekly and 3-weekly Cisplatin delivered concurrently with radical radiotherapy for head and neck cancer: a retrospective comparison from New Cross Hospital, Wolverhampton, UK. Acta oncologica. 2008; 47: 1513-8.
27. Teo PM, Chan AT. Treatment strategy and clinical experience. Seminars in cancer biology. 2002; 12: 497-504.

28. Yao JJ, Yu XL, Zhang F, Zhang WJ, Zhou GQ, Tang LL, et al. Radiotherapy with neoadjuvant chemotherapy versus concurrent chemoradiotherapy for ascending-type nasopharyngeal carcinoma: a retrospective comparison of toxicity and prognosis. Chinese journal of cancer. 2017; 36: 26.

29. Astolfi L, Ghiselli S, Guaran V, Chicca M, Simoni E, Olivetto E, et al. Correlation of adverse effects of cisplatin administration in patients affected by solid tumours: a retrospective evaluation. Oncology reports. 2013; 29: 1285-92.

30. Tao CJ, Lin L, Zhou GQ, Tang LL, Chen L, Mao YP, et al. Comparison of long-term survival and toxicity of cisplatin delivered weekly versus every three weeks concurrently with intensity-modulated radiotherapy in nasopharyngeal carcinoma. PloS one. 2014; 9: e110765.

31. Lu H, Peng L, Yuan X, Hao Y, Lu Z, Chen J, et al. Concurrent chemoradiotherapy in locally advanced nasopharyngeal carcinoma: a treatment paradigm also applicable to patients in Southeast Asia. Cancer treatment reviews. 2009; 35: 345-53.

32. Zhang B, Mo Z, Du W, Wang Y, Liu L, Wei Y. Intensity-modulated radiation therapy versus 2D-RT or 3D-CRT for the treatment of nasopharyngeal carcinoma: A systematic review and meta-analysis. Oral oncology. 2015; 51: 1041-6.

33. Moon SH, Cho KH, Lee CG, Keum KC, Kim YS, Wu HG, et al. IMRT vs. 2D-radiotherapy or 3D-conformal radiotherapy of nasopharyngeal carcinoma: Survival outcome in a Korean multi-institutional retrospective study (KROG 11-06). Strahlentherapie und Onkologie: Organ der Deutschen Rontgengesellschaft [et al]. 2016; 192: 377-85. 